Jesús Soria Caro

Universidad de Zaragoza

\title{
MUERTE Y VACÍO EN LA POESÍA ESPAÑOLA, ITALIANA Y ESLOVENA DEL SIGLO XX
}

El vacío metafísico provocado por el derrumbamiento del cristianismo produce una epifánica conciencia del «ser», una verdad vaciada de cualquier esperanza de trascendencia más allá de la muerte. Se produce un deseo nihilista de derruir las estructuras socio-morales tradicionales en las que la vivencia de la angustia del «ser» ante la «nada» marcará una nueva perspectiva del artista sobre la vida. Las ruinas morales de las dos guerras mundiales y su sangriento holocausto originan una crisis de conciencia. La sensación de vacío ofrece un nuevo escenario poético en el que el «ser» carece de la anestesia metafísica de la fe y proyecta su mirada ante la realidad del abismo. La poesía europea de posguerra nos presenta la condición prometeica del poeta como explorador del misterio, como poseedor del fuego de la verdad racionalista que nos descubre la soledad del hombre ante la «nada». $\mathrm{El}$ «ser» es un «semidios» que ha perdido la «inmortalidad». La reflexión, la razón y el pensamiento existencialista son los causantes de la caída, la manzana de un paraíso perdido que ha descubierto al hombre su desnudez mortal.

El existencialismo se filtra en las principales corrientes y creaciones de los poetas de la Europa de posguerra. Las consecuencias de la Guerra Civil española y posteriormente de la Guerra Mundial agravan la base de la angustia; el poeta está dominado por la duda, por la negación de un orden ideal. Con respecto a la poesía española, insertada en un marco tradicionalmente regido por valores religiosos, se ve asediada ante el derrumbamiento de los dogmas espirituales, que se habían asentado sobre la promesa de trascender la muerte. Hijos de la ira y Oscura noticia de Dámaso Alonso marcarán la inflexión hacia una poesía meditativa que gravitará sobre la obsesión de la muerte, del vacío provocado al no encontrar un sentido a la existencia. La actitud del poeta supondrá un interrogante existencial lanzado ante la nada, a un Dios ausente que, como Nietzsche declaró: «había muerto». Debemos precisar que, aunque Dámaso Alonso negó cualquier afiliación al existencialismo, en su obra se refleja la desolación del «ser» ante la muerte, la angustia surgida por la Guerra Civil y por la posibilidad de otra guerra mundial. Su poesía implanta una corriente de poesía reflexiva enfocada hacia el problema de la existencia, dominada por la atmósfera nietzschiana, por su teología negativa al situarse en el «vacío de Dios».

Surgirá una tensión existencial que sacudirá la conciencia del poeta, que se verá sometido a las leyes de la temporalidad. El pensamiento existencial proyectará las sombras del absurdo sobre el mundo interior del poeta, «ser» escindido entre la racionalidad y la necesidad de trascendencia, dominado por un conflicto forjado en su interioridad al asumir la verdad de un final inevitable: la caducidad del tiempo. La filosofía del siglo XX ofrecerá voces que se alzarán ante las ruinas de una espiritualidad perdida: pensadores como Heidegger, Sartre, Nietzsche o Kierkegaard ofrecen nuevas perspectivas sobre la problemática del «ser».

Nietzche planteó una ruptura sobre el pensamiento y los dogmas tradicionales, aportando nuevas claves sobre la condición patética del «ser». Así declarará «la muerte de Dios», entendiéndose dicha afirmación como la negación de la religión como esquema moral, atribuyéndole un valor mítico y trascendental negador de la vida. Esa muerte de Dios, la ine- 
xistencia de cualquier verdad trascendental, conduce a las sombras del absurdo, a la errancia de una luz que se extingue, marcando así una nueva concepción sobre la existencia. En El origen de la tragedia no encontramos únicamente una reflexión estética sino que su enfoque crítico se sitúa a un nivel radical más profundo; la pregunta por la condición de lo trágico conlleva a su vez un análisis de lo trágico como categoría existencial. Una lectura metafísica nos orienta hacia el fracaso del pensamiento sustentado en un orden trascendente; la vida no puede concebirse en función de ninguna verdad definitiva, como implicaba la metafísica idealista, como afirmará Nietzsche en Ecce homo: «En la misma medida en que se ha imaginado por una mentira al mundo ideal, se ha despojado a la realidad de su valor, de su significación, de su verdad» (1984: 27).

También el pensamiento de Heidegger será un referente para autores aquí estudiados como Miguel Labordeta, José Hierro. En Ser y tiempo, Heidegger ofrecerá una concepción del «ser» definida en el momento en que éste toma conciencia de sí mismo, así como Dasein (estar ahí) debe asumir una existencia que no ha elegido. Heidegger afirmará que tratamos de ocultar la muerte como la muerte de los otros, dotándola así de una impersonalidad que nos aleja de su realidad. Denuncia esta operación anestésica, no es posible su eufemismo, la realidad humana es la de un «ser-para-la muerte», muerte que, como señaló Gabriel Albiac, ocultamos mediante símbolos:

\begin{abstract}
¿Por qué «metáforas», «mitologías»,»símbolos»? ¿Por qué no la muerte, sin más? Porque de la muerte no es posible hablar de ningún modo y porque, cuando creemos estar nombrándola, no hacemos sino construir una mejor coartada que aún más nos la oculte. Sólo atravesando sus huellas desplazadas -en metáforas, en mitologías y símbolos- nos es posible apreciar la feroz herida con que ese muro infranqueable nos marca. (Albiac, 1990: 11)
\end{abstract}

La obra de Sartre ofrece un paradigma filosófico sobre el absurdo de la existencia, frente a Heidegger, Sartre no estaba interesado en la reflexión ontológica de la existencia sino que se propuso esbozar una filosofía del sujeto adecuada al tiempo, proponiendo así un planteamiento del existencialismo como visión del mundo. En El ser y la nada proclamó que la existencia del hombre conforma una rotura del ser sin fisuras, una nada (neant), tras la que el hombre debe enfrentarse a un mundo vaciado de sentido. En La náusea el héroe de la novela, Antoine Roquetin, es presentado en el lluvioso tedio de Bouville con la sensación de que todo lo que le rodea carece de sentido y de que nada en absoluto justifica su existencia. Esa «náusea» es la fractura interior que encontraremos en los versos de Dane Zanj, cuando siente que la vida ha dejado de tener sentido, el absurdo invade su percepción de la vida, dejamos de ser dioses, hemos perdido la inmortalidad. Esa misma «náusea» es la que en José Hierro provoca la búsqueda de un instante eterno, la necesidad de trascender la temporalidad mediante la creación lírica de un tiempo detenido, liberado del fluir de la temporalidad.

Frente a las perspectivas anteriores, Kierkegaard plantea la posibilidad de trascendencia, ofreciendo como única solución de la angustia la recuperación de la fe, la superación del racionalismo. En La repetición nos ofrece la escisión del hombre moderno mediante dos personajes, el esteta y el joven enamorado, ambos fruto del desdoblamiento de la conciencia, del enfrentamiento entre la razón y la fe: su pensamiento se dejará sentir en la poesía española de posguerra, especialmente en D. Alonso, V. Aleixandre y J. Hierro. En el caso de Hierro, Alegría se abre con el poema «Llegué al dolor por la alegría», una idea que le emparenta con el pensamiento de Kierkegaard, según el cual sólo con el do- 
lor cobramos conciencia de estar vivos: «Llegué por el dolor a la alegría.// Supe por el dolor que el alma existe» (Hierro, 1991: 13).

Tras estas precisiones filosóficas es el momento del análisis de la convergencia del pensamiento existencialista en la cosmovisión poética de algunos poetas españoles, italianos y eslovenos. Nuestro análisis sobre la influencia del existencialismo en la poesía europea se va a concretar en el análisis de poemas pertenecientes, entre otros, a los siguientes autores: Emilio Prados, José Hierro, Miguel Labordeta, Juan Eduardo Cirlot, Francisco Brines, Ángel Guinda, Dane Zajc, Milan Dekleva y Tomaso Kemeny.

Jardín cerrado, de Emilio Prados, ofrece reminiscencias bíblicas, su título nos plantea un juego de oposiciones con respecto a la Biblia, si el edén representa una visión del alma, el jardín cerrado es un retrato del cuerpo, de la materia, de la razón. Racionalidad que conduce al poeta a una soledad producida por la sombra perenne de la muerte, dicho jardín se presenta como un símbolo poético del cuerpo, que está herido por el tiempo y por la muerte, es el jardín de la tierra perdida, la sombra de la noche oscurece su espacio en el que el hombre, ser mortal, se sabe abocado a un final tal vez definitivo. En «Cantar del dormido en la hierba» aparece la imagen simbólica del cuerpo aprisionado por el tiempo, por la muerte:

\author{
La muerte está conmigo, \\ mas la muerte es jardín \\ cerrado, espacio, coto, \\ silencio amurallado \\ por la piel de mi cuerpo, \\ donde, inmóvil-almendra \\ viva, virgen-, mi luz \\ contempla y da la imagen \\ redimida, del fuego
}

Si he de morir, ya es muerte:

la estrella, la avenida, el silencio, la noche, el agua y el amor. (Prados, 2000: 213)

El hombre es un extranjero en una tierra del absurdo, en una realidad situada en una nada proyectada sobre un tiempo que se escapa. Destaca la fuerza lírica de otra de las composiciones del poemario, «Ciudad de sangre», en la que la ciudad es un espacio interior, el escenario de soledad y angustia que planteó Camus sobre la existencia del ser:

Si eras ciudad de silencio
y tu carne dolorida,
tierra del mundo, apretada
sobre tu angustia en semilla
¿por qué llamaste la luz?
Hoy eres ciudad vencida. (Prados, 2000: 215)

El poeta recurre a la imagen metafórica de «una cuidad vencida», símbolo de la conciencia vencida por el vértigo de la temporalidad imparable, por la cercanía de la muerte. La verdad de la temporalidad somete al poeta al dolor, a la angustia de saberse destinado a morir: 
Y tu soledad, se fue,

la soledad que querías,

a hacerse cuerpo del aire

-sombra de angustia cautiva- (Prados, 2000: 216)

La supremacía de la sombra se acentúa en el libro tercero; la sombra es el símbolo de la muerte como verdad inseparable que acompaña al poeta. Estos umbrales de oscuridad son un tránsito hacia lo desconocido. Sin embargo, el poeta debe aceptar su pertenencia a un tiempo limitado, la condición de su mortalidad. Si recurrimos a los términos heideggerianos, el sujeto lírico es el «ser» que, como Dasein, como ser «ek-sistente», sale de sí y se proyecta hacia el horizonte de la nada.

$\mathrm{El}$ «ser» se enfrenta al vacío, a la soledad de una existencia poblada de ausencias, de huellas de la nada, de un tiempo que se escinde. El poeta es un habitante de una realidad sin luz, de un espacio desértico para la esperanza. En la poesía de Dane Zajc encontramos la herida existencial del vacío que embarga al hombre ante la conciencia de una realidad vital carente de sentido. El absurdo invade la conciencia del ser y el poeta se sumerge en un océano de respuestas contaminadas, voces de la nada que responden al pensamiento nihilista. El eco de la barbarie, la violencia y sus devastadoras ruinas morales marcan una orientación ante un escenario social condicionado por la destrucción moral de la guerra. «La tierra me amará» es una proyección de la oscuridad de la mirada angustiada del poeta ante la idea de la vida como una representación teatral ante un escenario de sangre y violencia, el hombre es el personaje de este absurdo, su futuro se proyecta hacia ese abismo del final, a la desaparición del ser que retorna a la tierra, a la nada:

\author{
Mi cuerpo estará tan frío, \\ tan helado, \\ tan abandonado \\ Sólo la tierra amará mi cuerpo. \\ Con incontables manos me cubrirá. \\ Con incontables bocas me devorará. \\ Y entonces \\ no podrás decir \\ al terrón de tierra: \\ éste es su corazón \\ que me amó. (Slovenian Writers’ Association, 1995: 25)
}

La vida condicionada por su destino mortal es el absurdo que para Albert Camus surge como resultado de la confrontación entre los anhelos del ser y el contraste con la realidad. El ser en su infancia carece de conciencia de la muerte, ya que esta le es camuflada, siendo posteriormente un espectáculo en el que el «ser» contempla la desaparición de otros. El absurdo proviene según Camus de esta confrontación entre lo irracional de una vida carente de sentido y la desesperada ansia del ser por encontrar un significado a la existencia:

Mais ce qui est absurde, c'est la confrontation de cet irrationnel et de ce désir éperdu de clarté dont l'appel resoné au plus profond de l’homme. (Camus, 1942: 37) 
La búsqueda de este significado conlleva en la poesía de José Hierro la necesidad de trascender la temporalidad, lo que se constituirá en el elemento esencial de su cosmovisión poética. El flujo temporal es detenido mediante la superposición espacio-temporal. En «Alucinación» se superponen dos lugares distintos en el tiempo y el espacio fusionados en un solo recuerdo:

\author{
Imaginar y recordar... \\ Hay un momento que no es mío, \\ no sé si en el pasado, en el futuro, \\ si en lo imposible... Y lo acaricio, lo hago \\ presente, ardiente, con la poesía. \\ No sé si lo recuerdo o lo imagino. \\ (Imaginar y recordar me llenan \\ el instante vacío.) \\ Me asomo a la ventana, \\ fuera no es Dublín lo que veo, \\ sino Madrid \\ [...] \\ Y dentro, un hombre \\ sin nostalgia, sin vino, sin acción, \\ golpeando la puerta. (Hierro, 1986: 95)
}

Esta sensación de tiempo detenido, trascendido, alejado de la muerte, se nutre en la composición de varios procedimientos: la ya analizada superposición espacio-temporal, el empleo de pocos y verbos que se repiten (imaginar, recordar) y las continuas enumeraciones de nombres (un hombre sin nostalgia, sin vino, sin acción) se aúnan para producir la sensación de un tiempo vivo, detenido.

En Las brasas, de Francisco Brines, también está presente la reflexión sobre el tiempo. Es una obra que se nutre del pensamiento existencial, que gravita sobre la certidumbre de que la vida está hecha sólo de tiempo. Las composiciones que lo integran suponen un retrato de distintos momentos de la vida que, para José Olivio Jiménez, debe entenderse como: «un movimiento de caída, de precipitación inexorable hacia la muerte o la nada, con simbólicas (y reiterativas) referencias a la circunstanciación de donde esos fragmentos poemáticos han surgido» (Jiménez, 2001: 24). Otro aspecto también abordado por José Olivio Jiménez ha sido la correlación simbólica que se establece entre el comienzo y el final de los textos y el inicio y el final de la existencia. A este respecto, encontramos en «El visitante me abrazó» un desarrollo de la estructura poemática en el que se traza un paralelismo existencial con el orden temporal que rige el desarrollo de la vida. El comienzo del poema nos presenta un sujeto lírico, «el visitante», que simboliza la juventud y al final de la composición se nos retrata a dicho visitante afirmando: «que tiene viejo el corazón». Es decir, «el visitante», alegoría del tiempo, es al inicio del poema (correlato simbólico del inicio de la vida) un personaje dotado de la fuerza de la juventud. Sin embargo, al final de la composición (correlato simbólico de la muerte) dicho «visitante» aparece cansado, agotado por el tiempo. Es ahora un hombre anciano, presentado en términos de cansancio existencial, el sujeto lírico representa la condición del hombre definida en 
La náusea por Sartre, la de un ser que nace en unas circunstancias que no puede elegir, constituyendo el hecho mismo de su existencia un absurdo:

\author{
El visitante me abrazó, de nuevo \\ era la juventud que regresaba, \\ y se sentó conmigo. Un cansancio \\ venía de su boca, sus cabellos \\ traían polvo del camino, débil \\ luz en los ojos. Se contaba a sí mismo \\ las tristes cosas de su vida, casi \\ se repetía en él mi pobre vida \\ Arropado en las sombras lo miraba. \\ La tarde abandonó la sala quieta \\ cuando partió. Me dije que fue grato \\ vivir con él (la juventud ya lejos), \\ que era una fiesta de alegría. Solo \\ volví a quedar cuando dejó la casa. \\ Vela el sillón la luna, y en la sala \\ se ven brillar los astros. Es un hombre \\ cansado de esperar, que tiene viejo \\ su torpe corazón, y que a los ojos \\ no le suben las lágrimas que siente. (Brines, 1999: 25)
}

La meditación sobre la muerte es uno de los temas principales de la poesía de Miguel Labordeta, una escritura poética en la que la concepción del tiempo de Heidegger está presente de manera destacada: «Elegía a mi propia muerte», «Asesinados jóvenes» y «Agonía del existente Julián Martínez». Para reconstruir el sentido filosófico de su obra debemos partir del concepto heideggeriano del Dasein, que se refiere a que el «ser» como existente sale de sí mismo para proyectarse hacia el mundo, hacia un futuro cuyo desenlace lo constituye la muerte. «Dasein» es también el título de una composición en la que el poeta se ve como un «ardiente imperfecto», el yo lírico se muestra herido por la conciencia del tiempo, por el vacío ontológico del ser.

El poeta se define en términos del Dasein: su esencia radica en la Existenz, y se pregunta por el sentido del ser (Sinn des Seins), prevaleciendo una crisis espiritual y existencial sobre la que se sustentará la propuesta poética de sucesivos textos:

Ardiente imperfecto, me deshabito en el internado brutal de las metamorfosis.

Se diría que todo

fue una dolorosa mentira:

El amor y la vida, la música y el árbol, lo distante y mi entraña ida entre la intensa búsqueda de esta honorable tarde difunta. (Labordeta, 1994: 111) 
En «Hombre sin tesis» la presencia de esta crisis surge debido al conflicto entre angustia y esperanza trascendente. Hay sedimentos de una ideología cristiana enfrentados al nihilismo y a la queja desgarrada:

\author{
Hombre sin tesis \\ heme aquí desconchado \\ en los hoyos del ser consumido \\ esperando letárgico ese volver atrás \\ de la ceniza pura en los imaginarios buzones \\ que llamamos tiempo \\ o plasmar mudo del olvido. \\ Heme aquí llamando a Dios \\ por teléfonos oscuros \\ de mis centros impalpables. (Labordeta, 1994: 89)
}

En la obra de algunos poetas novísimos (Guillermo Carnero, Ánguel Guinda, etc.) también podemos percibir la violencia abismática surgida ante la velocidad del tiempo, ante la realidad de la muerte. Ese vértigo de la existencia se olvida mediante la creación de mundos autónomos, la introducción de elementos culturalistas como referencias al cine o poemas ambientados en lejanos y exóticos lugares. La identidad del poeta termina revelándose en el proceso de creación en el que se produce el descubrimiento de uno mismo, descubrimiento de la conciencia del «ser», la afirmación heideggeriana del hombre como «ser» que asume su muerte. En la poética de Felipe Benítez Reyes para la antología El último tercio de siglo encontramos la alusión a la poesía como un proceso que supone la escritura simultánea de ese tiempo hacia la nada, una huella de la muerte, de ese sinsentido marcado en nuestra conciencia:

Desde que escribo la palabra infinitud,

en este instante

(y designo con ella en mi memoria

todo cuanto no cesa ni se extingue,

como el mar infecundo o como el fuego,

como el hondo venero sin final ni principio

de todas nuestras vidas, misteriosas y breves;

como todos los versos que han sonado

-a lo largo de siglos minuciosos-

en nuestro descorazonado espíritu

igual que el aleteo de un millar

de mariposas psicóticas),

desde que escribí la palabra infinitud,

hace un instante, hasta que escribo

estas otras palabras, le he robado ya al tiempo

una porción de irrealidad

infinita como un desierto de arenas de oro frío

que volasen por el cielo de plata

en los días de viento poderoso,

igual que por el aire va la música abriendo

su gran rosa sonora y sin sentido. (apud Mainer, 1998: 708) 
Guillermo Carnero, en Dibujo de la muerte, encuentra en la belleza un medio para olvidar la muerte. Sin embargo la dicotomía belleza/muerte implica la oposición entre la vida, regida por la temporalidad, y la belleza, que se sitúa más allá de las consecuencias de la temporalidad. Ya en la primera composición, «Ávila», encontramos una descripción de la tumba del príncipe Don Juan, hijo de los Reyes Católicos. La belleza de la tumba contrasta con la aridez y la oscuridad del paraje en el que se sitúa. El arte y la belleza no son, como el título de la obra indica, más que un dibujo de la muerte, un reflejo de la vida sometida a las leyes del tiempo:

\author{
En Ávila la piedra tiene cincelados pequeños corazones de \\ nácar. \\ y pájaros de ojos vacíos, como si hubiéramos sido el hierro \\ martilleado por Fancelli \\ [...] \\ Hay algún bar abierto en donde suena un disco. \\ Es tan vasto tu reino que no puede llenarte. (1998: 97-98)
}

Hay, por tanto, un juego de oposiciones entre la belleza del arte, perdurando este último más allá del tiempo, y la decadencia del hombre destinado a la muerte. Así, la desolación del poeta se oculta tras la máscara del refinamiento, de la belleza, resultando ser esta un «dibujo», un producto estético que, al establecer el contraste entre belleza y muerte, profundiza en el carácter perecedero de la existencia. También encontramos en esta lírica de finales del siglo XX rasgos poéticos de los denominados trazos del silencio, éste aparece nominalizado aludiendo a la nada, a la muerte, al vacío de sentido. La realidad es un orden existencial inefable, una experiencia caótica intraducible. Ángel Guinda en su poemario Biografía de la muerte nos ofrece la imagen del silencio como esa realidad final cuya morada se encuentra en la nada; su título, «La puerta del silencio», simboliza la entrada final del ser en sus dominios: "«Somos gotas de sed/ ecos de un resplandor.// Frente al mar todos callan»/...Así comienza la historia del adiós” (Guinda, 2001: 17).

Es relevante la relación que se establece entre eros y thánatos en la poesía contemporánea. El amor y la experiencia erótica suponen una experiencia liberadora de la muerte. En la obra de Juan Eduardo Cirlot es esencial la dicotomía amor/muerte. La base filosófica de su pensamiento poético reside en la construcción de un sistema de pensamiento basado en la idea del ser enfrentado a las limitaciones del «yo» para lograr acceder a la verdadera concepción del «ser», para lo que es necesario la superación de los límites temporales y existenciales. El primer paso se encuentra en la destrucción del tiempo. Pero la verdadera clave para lograr que se desvanezca el mundo sometido a las leyes de la existencia temporal se encuentra en la intuición amorosa. El amor permite el acceso a un absoluto fuera del tiempo, es la posibilidad de renacer eternamente. Al inicio de «Desde donde te miro» encontramos un tormento que se asocia a «ciudades negras» y un cuerpo ataviado con un «vestido de acero», sin duda símbolos de la temporalidad que apresa al ser:

No sé de qué ciudades negras procede este tormento

de qué negras ciudades con torres encarnadas

ni sé con qué vestido de acero indescriptible

mi cuerpo se ha ataviado, severamente duro. (Cirlot, 1981: 68) 
Es destacable en su obra la presencia simbólica de la mujer, que inicialmente se presenta como la doncella que constituye ese ser «otro» capaz de abolir la realidad del tiempo. Pero pronto se produce un dualismo y aparece una figura femenina relacionada con la magna mater y que representa la unión de eros y thánatos:

$\mathrm{O}$ ven tú solamente doncella de mis ruinas

palacio de transparentes sienes

e incendia mis cabellos y mi mágica pena

con una de tus largas miradas o azabaches.

Destruye mis cadenas con tus látigos finos desciende a mis recintos de cemento rabioso y quiébrame despacio con el puñal profundo. (Cirlot, 1981: 70)

En la poesía de Tomaso Kemeny también encontramos esta idea del amor como una experiencia erótica liberadora de la muerte, la ambrosía que calma el anhelo del ser de trascender los límites de su existencia, los estragos del tiempo. En «La pasión es luz» se alude en los versos iniciales a la idea del fuego como elemento que borra la memoria, esa conciencia existencial del tiempo y la nada, el fuego es así el símbolo del amor y del olvido de la muerte:

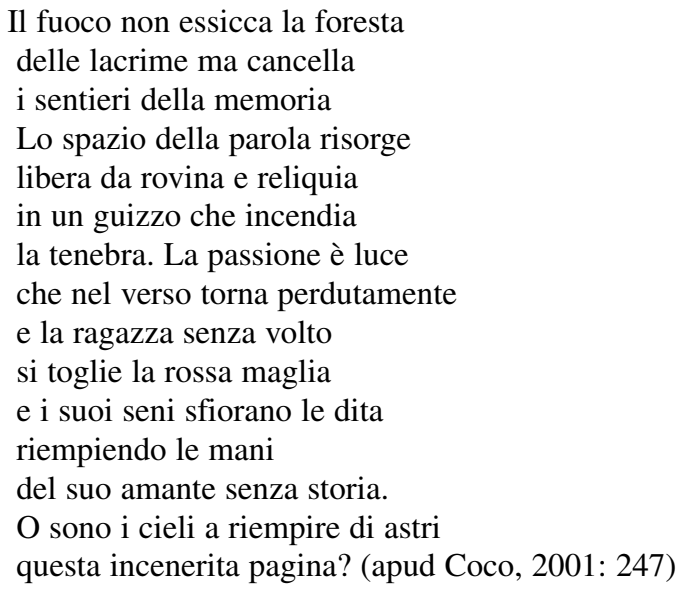

La amante permite al amado liberarse de la temporalidad ya que al rozar sus senos éste es presentado como «su amante sin historia», no existe el pasado y, como se nos ha recordado anteriormente, la palabra resurge: «libre de ruina y reliquia/ en un destello que enciende/ las tinieblas». Estas ruinas son las de la existencia, el territorio de escombros que supone la nada, esas «tinieblas» son iluminadas con el fuego del deseo.

El abandono de las esperanzas trascendentales y el fracaso de lo paraísos materiales han desembocado en la crisis moral de una existencia marcada por el absurdo, la vida es una ficción que nos acerca a la desaparición, a la ausencia de la promesa de eternidad dictada por las religiones. El existencialismo ha configurado un nuevo orden de pensamiento en el que la sensación del vacío invade la conciencia del ser. El «ser» se presenta aislado ante la nada, habitando sin remedio un cuerpo destinado a la muerte. Hay una irreducti- 
ble sombra proyectada sobre el absurdo que lo asedia en su trayecto vital. El vértigo existencialista surgido tras la pérdida de las verdades dogmáticas da lugar a una poesía meditativa. El poeta, que es consciente de la temporalidad de la existencia, se siente dominado por la angustia, por la náusea sartreana que invade la conciencia del «ser». La voz del poeta debe enfrentarse a la realidad de la muerte, en su tránsito por las sombras de la duda debe elegir entre aceptar el impulso ontológico de salvación proporcionado por la fe que planteaba Kierkegaard o aceptar que el hombre es un «ser» destinado a la muerte, como afirmaba Sartre.

\section{BIBLIOGRAFÍA}

Albiac, G. (1990): La muerte: metáforas, mitologías, símbolos. Barcelona: Paidós.

Albornoz, A. de (1982): José Hierro. Barcelona: Júcar.

Brines, F. (1989): El rumor del tiempo. Prólogo de D. Cañas. Madrid: Mondadori.

Brines, F. (1999): Poesía completa. Barcelona: Tusquets.

Camus, A. (1942): Le mythe de Sisyphe. París: Gallimard.

Cirlot, J. E. (1981): Obra poética. Madrid: Cátedra.

Coco, E. (2001): El fuego y las brasas: poesía italiana contemporánea. Madrid: Celeste Sial.

Guinda, Á. (2001): Biografía de la muerte. Madrid: Huerga y Fierro.

Hierro, J. (1991): Alegría. Madrid: El vaso de Berceo.

Hierro, J. (2002): Antología poética. Madrid: Alianza.

Jiménez, J. O. (2001): La poesía de Francisco Brines. Sevilla: Los cuatro vientos.

Labordeta, M. (1994): Donde perece un dios estremecido. Ed. de A. Pérez Lasheras y A. Saldaña. Zaragoza: Mira Editores.

Mainer, J. C. (1998): El último tercio de siglo: Antología consultada de la poesía española. Madrid: Visor.

Nietzsche, F. (1984): Ecce homo, ed. de A. Sánchez Pascual. Madrid: Alianza.

Prados, E. (2000): Jardín cerrado. Madrid: Cátedra.

Sartre, J. P. (1968): El ser y la nada. Buenos Aires: Losada.

Slovene Writers`Association (1995): Poesía eslovena contemporánea. Ljubljana: Slovenian literary magazine.

\section{SMRT IN PRAZNINA V ŠPANSKI, ITALIJANSKI IN SLOVENSKI POEZIJI 20. STOLETJA}

Članek analizira vpliv eksistencialne misli na nekatere predstavnike španske, italijanske in slovenske poezije 20. stoletja. Avtor sledi Nietzschejevi, Heideggerjevi in Sartrovi misli in v okviru te filozofije predstavi pesnike, pripadnike različnih kultur, literarnih tradicij in jezkovnih okolij. Študija se usmerja v sodobnega pesnika, ki je zapustil vero v transcendentni red in se sooča z ničem, z eksistenco, ki jo pojmuje kot absurd. Pesnik mora sprejeti, da idealno upanje ne obstaja. Eksistencialna filozofija - na to dejstvo nas opozarjajo analizirani pesniki v tem prispevku - pa ponuja nove odgovore na vprašanje biti. 